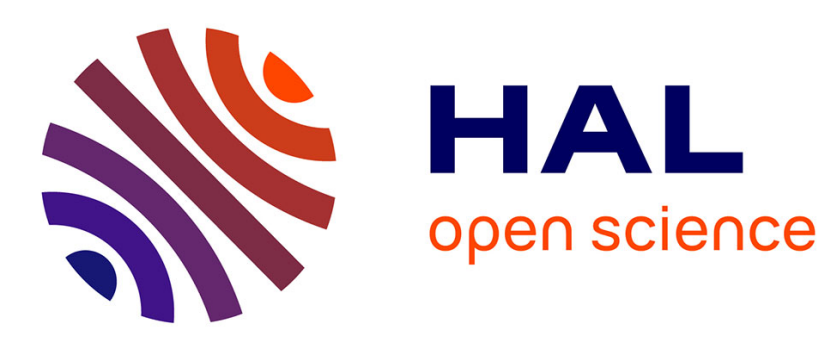

\title{
Calibration free and fluorescein based fiber optic pH sensor for clinical applications
}

Bernard Manuel, Rutjaphan Kateklum, Bruno Wacogne

\section{To cite this version:}

Bernard Manuel, Rutjaphan Kateklum, Bruno Wacogne. Calibration free and fluorescein based fiber optic pH sensor for clinical applications. IEEE SENSORS, Oct 2018, New Delhi, India. hal-02130170

\author{
HAL Id: hal-02130170 \\ https://hal.science/hal-02130170
}

Submitted on 15 May 2019

HAL is a multi-disciplinary open access archive for the deposit and dissemination of scientific research documents, whether they are published or not. The documents may come from teaching and research institutions in France or abroad, or from public or private research centers.
L'archive ouverte pluridisciplinaire HAL, est destinée au dépôt et à la diffusion de documents scientifiques de niveau recherche, publiés ou non, émanant des établissements d'enseignement et de recherche français ou étrangers, des laboratoires publics ou privés. 


\title{
Calibration free and fluorescein based fiber optic $\mathrm{pH}$ sensor for clinical applications
}

\author{
Bernard Gauthier-Manuel ${ }^{1}$, Rutjaphan Kateklum ${ }^{1}$, Bruno Wacogne ${ }^{1,2}$ \\ ${ }^{1}$ FEMTO-ST institute, Univ. Bourgogne Franche-Comte, CNRS, 15B avenue des Montboucons, 25030 Besancon, cedex, France \\ ${ }^{2}$ INSERM CIC 1431, Besancon University Hospital, 25000 Besancon, France
}

\begin{abstract}
This communication describes how fluorescein grafted at the end of an optical fiber can be used for calibration free $\mathrm{pH}$ sensing in the range of physiological values. The method is based on a complete mathematical description of the fluorescence mechanisms of this $\mathrm{pH}$ indicator. The analysis of the shape of the fluorescence spectra allows computing values of both the pH and the pKa3. Doing this, it becomes possible to access calibration $\mathbf{p H}$ sensing using conventional optical fibers. This is, to the best of our knowledge, the first fiber optic calibration free pH sensor reported to date.
\end{abstract} fiber

Keywords-pH sensing; calibration free; fluorescein; optical

\section{INTRODUCTION}

Because $\mathrm{pH}$ modification of the body fluids maybe the cause or the consequence of various pathologies, clinical staff looks for minimally invasive $\mathrm{pH}$ sensors which can be used in the human body for diagnosis, screening or monitoring. Together with the minimal invasiveness aspect of the ideal $\mathrm{pH}$ sensor, the latter must be operated in a calibration free manner because clinical examination are not conducted in a laboratory environment.

In order to meet these requirements, optical fiber based $\mathrm{pH}$ sensors have been reported for several years [1-4]. In this technology, $\mathrm{pH}$ sensitive indicators are grafted at the end of an optical fiber and $\mathrm{pH}$ is deduced from the fluorescence behavior of the indicators (fluorescence intensity or spectra analysis). Mostly 2 kind of indicators are used. The first family concerns indicators exhibiting a single emission peak. $\mathrm{pH}$ is related to the intensity measured at the unknown $\mathrm{pH}$ normalized by the intensity at high $\mathrm{pH}$ values. This is the case of fluorescein for example [5]. A priori, this indicator cannot be used for calibration free measurements. However, we will see later that under certain conditions, this statement is no longer valid. The second family concerns indicators with a double emission peaks. Each peak corresponds to either fully protonated or fully deprotonated forms of the molecules. Measuring the ratio of the intensities at the 2 peak wavelengths allows calculating the $\mathrm{pH}$ value. This is the case of SNARF® (seminaphtarhodafluor) for example [2]. This ratiometric technique is however not calibration free and molecule manufacturers advise users to perform a pre-calibration using the acidic and basic endpoints of titration respectively. This calibration procedure requires

This work was partially supported by the European Commission [grant number H2020-SC1-2017, operation 754907]. controlling very accurately the experimental conditions and cannot be envisaged in clinical applications.

Among different reasons, calibration is required to account for degradation of the sensor probe due to aging or repetitive use. In fact, $\mathrm{pH}$ sensing is based on the monitoring of the acidbase reaction which occurs in the indicator layer grafted at the end of the optical fiber. Calibration is required because the $\mathrm{pKa}$ of the acid-base reaction cannot be considered constant. $\mathrm{pKa}$ variations are due to several factors like temperature and/or ionic strength of the solution to be measured, structure and thickness of the indicator layer at the end of the fiber. Indeed, pKa can differ by almost 2 units between the value in a low concentration solution and the value in a dense layer, close to a solid surface, which is the case in fiber optic $\mathrm{pH}$ sensors [6].

Some authors proposed a more mathematical description of fluorescence properties. In [7] for example, authors propose to extend the 2 wavelengths ratiometric method to the analysis of the whole fluorescence spectrum. Their approach consists in computing the spectra of both fully protonated and fully deprotonated forms of SNARF®. These 2 extreme $\mathrm{pH}$ spectra form a basis which is now used to fit a spectrum recorded at an unknown $\mathrm{pH}$. However, variation of the $\mathrm{pKa}$ are not accounted for and calibration free measurement is not obtained. In [8, 9] authors employ the same method. Their approach is more "chemimathematic" because they consider 2 phenomena playing a role in $\mathrm{pH}$ determination: shifts of fluorescence wavelengths and intensities and variations of the $\mathrm{pKa}$ value. In order to account for the real $\mathrm{pKa}$ value, authors measure spectra obtained with perfectly known $\mathrm{pH}$ solutions. The value of $\mathrm{pKa}$ is subsequently computed using the HendersonHasselbach equation. However, computing the $\mathrm{pKa}$ value using solutions of known $\mathrm{pH}$ means conducting calibration experiments.

In this communication, we show that modeling the fluorescence properties of ratiometric indicators existing in their 2 acidic and basic forms cannot be used to access calibration free $\mathrm{pH}$ sensing. We then explain how fluorescein, which exhibits more complex prototropic equilibria, can be used to compute not only the $\mathrm{pH}$ value but also the value of the $\mathrm{pKa}$ at the moment when measurements are performed. We present the complete mathematical modeling of the fluorescence properties of fluorescein using a set of fibers, and we present application of the model test fibers which were not used to elaborate the mathematical model. 


\section{CALIBRATION FREE PH SENSING BY MODELING THE EMISSION SPECTRA}

\section{A. Indicators exhibiting only 2 prototropic forms}

As we briefly mentioned, ratiometric indicators usually exist under 2 prototropic forms: fully protonated or fully deprotonated. Each of these forms exhibits different fluorescence emission spectra. Depending on their relative concentration, the resultant spectrum allows measuring the $\mathrm{pH}$ by calculating the ratio of the emitted intensities at 2 distinct wavelengths. More precisely, $\mathrm{pH}$ can be determined by studying the whole shape of the spectrum and not only the intensities at 2 wavelengths. We also mentioned that calibration is required in order to account for $\mathrm{pKa}$ variations which occur during the life time of the sensor. Indeed, the equilibrium between protonated and deprotonated forms is governed by the law of mass action through the dissociation degree given by:

$$
\left.\alpha=1 /\left(1+\left[H^{+}\right] / K_{a}\right)\right)=1 /\left(1+10^{(p K a-p H)}\right)
$$

Here, $\mathrm{Ka}$ is the dissociation constant. It can clearly be understood that, whatever the method used to study the shape of fluorescence spectra, it is impossible to de-correlate the value of the $\mathrm{pH}$ from the value of the $\mathrm{pKa}$. Indeed, the only accessible variable is the ratio $\left[\mathrm{H}^{+}\right] / \mathrm{pKa}$ or the difference $(\mathrm{pKa}-\mathrm{pH})$. Consequently, it is impossible to access calibration using $\mathrm{pH}$ indicators exhibiting only 2 prototropic forms.

\section{B. Need for more complex prototropic equilibria}

A way to overcome this problem is to use $\mathrm{pH}$ indicators exhibiting more complex prototropic forms. This is the case of fluorescein which exhibits cationic, neutral, monoanionic and dianionic forms. Here, there exist 3 dissociation constants, each of them concerning the conversion from one form to another one. Therefore, the laws of mass action are more complicated. Equations (2) and (3) show the concentrations in monoanion $\left(\mathrm{HFlu}^{-}\right)$and dianion $\left(\mathrm{Flu}^{2-}\right)$ as a function of $\mathrm{pH}$ and $\mathrm{pKa}_{\mathrm{s}}$.

$$
\begin{aligned}
& {\left[\mathrm{HFlu}^{-}\right]=\frac{\left[\mathrm{FLU}_{\text {total }}\right]}{\frac{\left[\mathrm{H}^{+}\right]^{2}}{K a_{1} K a_{2}}+\frac{\left[\mathrm{H}^{+}\right]}{K a_{2}}+1+\frac{K a_{3}}{\left[\mathrm{H}^{+}\right]}}} \\
& {\left[\mathrm{Flu}^{2-}\right]=\frac{\left[\mathrm{FLU}_{\text {total }}\right]}{\frac{\left[\mathrm{H}^{+}\right]^{3}}{K a_{1} \mathrm{Ka}_{2} \mathrm{Ka}_{3}}+\frac{\left[\mathrm{H}^{+}\right]^{2}}{K a_{2} \mathrm{Ka}_{3}}+\frac{\left[\mathrm{H}^{+}\right]}{K a_{3}}+1}}
\end{aligned}
$$

We only give equations concerning the mono and dianion because only these 2 forms are fluorescing. It can be noted that the concentrations in fluorescent forms are related to the $\mathrm{pH}$ and dissociation constants in a nonlinear way. This allows decorrelating $\mathrm{pH}$ and $\mathrm{pKa}_{\mathrm{s}}$ when studying the shape of fluorescence spectra.

Concentrations of the different prototropic forms depend on the 3 dissociation constants. To simplify, $\mathrm{pKa}_{1}=2.22$ principally dictates the proportion between cationic and neutral forms, $\mathrm{pKa}_{2}=4.34$ the proportion between neutral and monoanionic forms and $\mathrm{pKa}_{3}=6.68$ between the mono and dianionic forms. The fluorescence spectra depend not only on the concentration in mono and dianion but also on the molar absorptivities and quantum efficiencies of these forms. The dianion fluoresces about 7 times stronger than the monoanion. When used at low concentration in solutions of low ionic strengths, $\mathrm{pKa}_{\mathrm{s}}$ of fluorescein can be considered constant. At physiological $\mathrm{pH}$ values with $\mathrm{pKa}_{3}=6.68$, mostly the dianion produces a fluorescence signal. Therefore, the shape of the fluorescence spectra remains constant for any $\mathrm{pH}$ value. This is why, up to now, measuring $\mathrm{pH}$ with fluorescein is based on the relative fluorescence intensity measurements as explained in the introduction. Indeed, in solution, studying the shape of the fluorescence spectrum is useless because it does not depends on $\mathrm{pH}$. It is then usually considered that fluorescein cannot be used to access calibration free measurement.

However, when grafted close to a surface, the $\mathrm{pKa}_{\mathrm{s}}$ of fluorescein can shift of about 2 units [6]. Because we consider physiological $\mathrm{pH}$ values, we only consider variations of $\mathrm{pKa}_{3}$. Fig.1 shows the relative fluorescence intensities of mono and dianion for variations of $\mathrm{pKa}_{3}$ around its value in solution. It can clearly be seen that the fluorescence contribution of the monoanion strongly increases with $\mathrm{pKa}_{3}$.
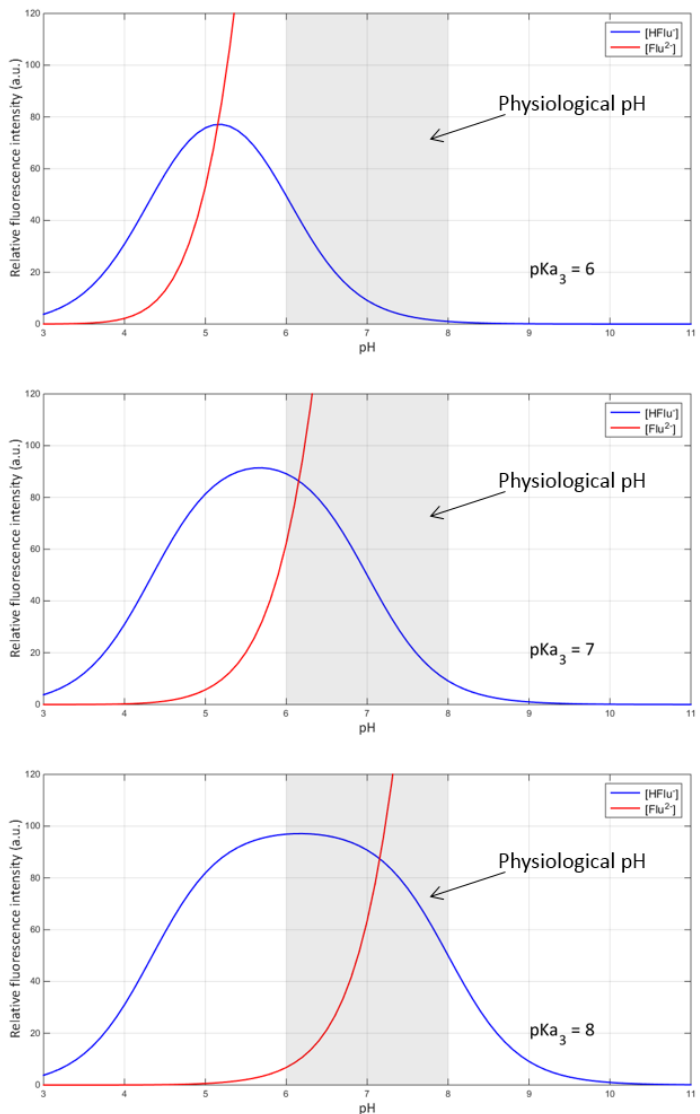

Fig. 1. Evolution of the fluorescence intensities of the mono and dianion with $\mathrm{pKa}_{3}$. Red curve: contribution of the dianion. Blue curve: contribution of the monoanion. The grey area represents the physiological $\mathrm{pH}$ window. 
The key point of this communication is based on this observation. When grafted onto a fiber, fluorescein exhibits 2 fluorescent forms producing fluorescence spectra of different shapes. The shape of the global fluorescence spectrum now evolves with the $\mathrm{pH}$ value. Therefore, the idea is to determine a mathematical function which describes the shape of the global fluorescence spectra as a function of $\mathrm{pH}$ and $\mathrm{pKa}_{3}$ which are considered as variables. Because we focus on physiological $\mathrm{pH}$, the other $\mathrm{pKa}_{\mathrm{s}}$ are considered constant. Once this $F l u\left(p H, p \mathrm{Ka}_{3}\right)$ function is established, it can be used to fit any fluorescence spectrum obtained at unknown $\mathrm{pH}$ with any fluorescein grafted fiber. $\mathrm{pH}$ and $\mathrm{pKa}_{3}$ values being decorrelated as explained above, it is possible to compute their values using a simple fitting of the recorded spectrum.

Practically, fluorescence spectra obtained with 8 different fibers and with solutions of $\mathrm{pHs}$ in the physiological range are used to define the $F l u\left(p H, p K a_{3}\right)$ function. Note that each fiber exhibits its own $\mathrm{pKa}_{3}$ value because of unavoidable variations of the fabrication process. We found out that 5 gaussian profiles were required to fully describe any fluorescence spectrum. Monoanion and dianion are described with 3 and 2 gaussian profiles respectively. The amplitudes related to both forms are fixed by the laws of mass action, molar absorptivities and quantum efficiencies. Amplitude coefficients are used to account for variations of the fluorescein concentration at the end of the fibers. Values of the $\mathrm{pKa}_{1}$ and $\mathrm{pKa}_{2}$ are fixed. $\mathrm{pH}$ and $\mathrm{pKa}_{3}$ are considered as variables. Other parameters concern positions and widths of the spectra of both prototropic forms. They depend on the thickness and structure of the fluorescein layer at the end of the fiber. They must be considered as variables.

Once the $F l u\left(p H, p \mathrm{Ka}_{3}\right)$ function is fully defined with the first 8 "model" fibers, it is used to fit the spectra obtained with other "test" fibers. Fig. 2 shows an example of such a fitting for a fiber immersed in a buffer solution of $\mathrm{pH} 7$. The fitting returns a $\mathrm{pH}$ value of 7.02 and a $\mathrm{pKa}_{3}$ value of 7.99 (to be compared to 6.68 for the fluorescein in solution). This example shows a calibration free $\mathrm{pH}$ measurement which accounts for variability of the $\mathrm{pKa}_{3}$ value due to fabrication variability and/or sensing layer aging.

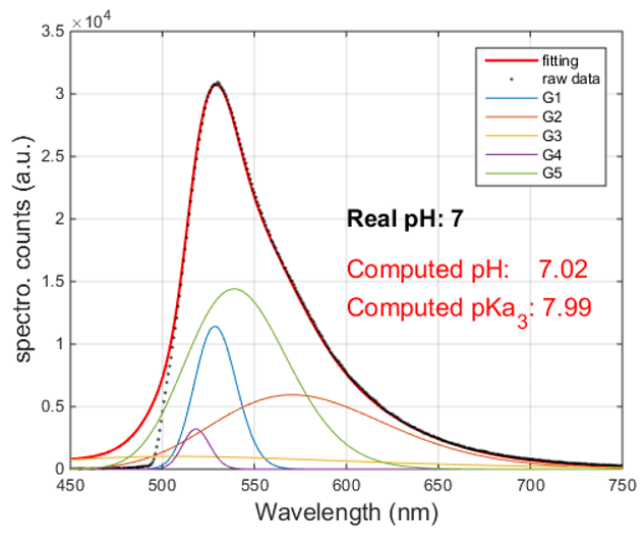

Fig. 2. Use of the Flu $\left(\mathrm{pH}, \mathrm{pKa}_{3}\right)$ function to fit a fluorescence spectrum obtained with a solution at $\mathrm{pH} 7$ with a fiber of unknown $\mathrm{pKa}_{3}$. Black dots: raw data. G1 ...G5: gaussian profiles. Red curve: fit result $=\mathrm{G} 1+\ldots+\mathrm{G} 5$.

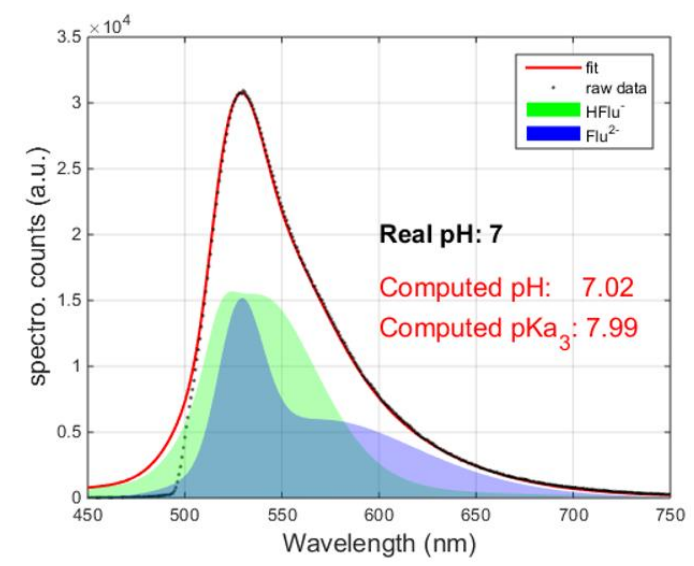

Fig. 3. Contribution of the mono and dianion to the whole fluorescence spectra. Green: monoanion. Blue: dianion.

Fig. 3 shows the calculated contributions of the 2 fluorescing forms of fluorescein. Overall, not only the $\mathrm{pH}$ and the $\mathrm{pKa}_{3}$ are fitted. It is necessary to fit 14 other parameters used to define the $F l u\left(p H, p K a_{3}\right)$ function. Some parameters used in the function are fixed and not considered as variables. Experiments conducted up to now show a $\mathrm{pH}$ and $\mathrm{pKa}_{3}$ determination accuracy less than 0.1 unit. The accuracy can further be improved by refining parameters values using a larger number of "model" fibers and by considering other $\mathrm{pKa}_{\mathrm{s}}$ as variables.

\section{DISCUSSION AND CONCLUSION}

These results constitute what is, to the best of our knowledge, the first demonstration of a calibration free fiber optic pH sensor. It could be objected that the $\mathrm{pH}$ we measure is the $\mathrm{pH}$ in the sensing layer and not the $\mathrm{pH}$ in the solution to be measured. But, relation between the $\mathrm{pH}$ in the sensing layer and the $\mathrm{pH}$ in the solution is accounted for when determining the parameters of the $F l u\left(p H, p K a_{3}\right)$ function.

More generally, literature concerning fiber optic $\mathrm{pH}$ sensor is relatively old (about 2 decades) and it seems that authors did not pursue their efforts in this domain. At that time, experimental set-ups, including lasers, monochromators and bulk spectrometers were too large to envisage the use of such sensors in clinical situations. Nowadays, compact apparatuses are available and applications in medical environment can be envisioned. More importantly today, computing capabilities of conventional computers allow including efficient fitting algorithms in the proposed medical devices.

In this communication, we put to profit this current experimental environment to set-up a calibration free $\mathrm{pH}$ sensor. For this, we use fluorescein, a robust and cost effective indicator considered as a single emission peak indicator, unable to provide calibration free measurements. Here, we show that it can be used for calibration free measurements. The condition for this is to graft it close to a surface in order to shift the values of the $\mathrm{pKa}_{\mathrm{s}}$. Indeed, grafting is exactly what we need for non-invasive intracorporeal $\mathrm{pH}$ sensing. Our current studies also concern calibration free ion sensing, in particular $\mathrm{Li}^{+}$ sensing for application in psychiatry. 


\section{REFERENCES}

[1] Y. Kawabata, K. Tsuchida, T. Imasaka, N. Ishibashi, "Fiber-optic pH sensor with monolayer indicator", Analytical Sciences, Vol. 3, pp 7-9, 1987.

[2] K.P. Dobmeier, G.W. Charville, M.H. Schoenfisch, "Nitric OxideReleasing Xerogel-Based Fiber-Optic pH Sensors". Analytical chemistry, vol. 78, pp.7461-7466, 2006.

[3] I. Kasik, J. Mrazek, T. Martan, M. Pospisilova, O. Podrazky, V. Matejec, et al., "Fiber-optic $\mathrm{pH}$ detection in small volumes of biosamples", Anal Bioanal Chem Vol. 398, pp 1883-1889, 2010.

[4] I. Chen, Q. Yang, H. Xiao, H. Shi, Y. Ma, "Local pH monitoring of small cluster of cells using a fiber-optic dual-core micro-probe", Sensors and Actuators B: Chemical, Vol. 241, pp. 398-405, 2017.

[5] H. Diehl, R. Markuszewski, "Studies on fluorescein-VII", Talanta, Vol. 36, pp. 416-418, 1989.
[6] C. Rottman, M. Ottolenghi, R. Zusman, O. Lev, M. Smith, G. Gong, et al., "Doped sol-gel glasses as pH sensors", Materials Letters, Vol. 13, pp. 293-298, 1992

[7] A.C. Ribou, J. Vigo and J.M. Salmon, "C-SNARF-1 as a fluorescent probe for $\mathrm{pH}$ measurements in living cells: two-wavelength-ratio method versus whole-spectral-resolution method", J. of Chem. Educ., Vol. 79, pp. 1471-1474, 2002.

[8] C. S. Owen, "Comparison of spectrum-shifting intracellular $\mathrm{pH}$ probes 5 (and 6 ' )-carboxy-10-dimethylamino-3-hydroxyspiro[7H-

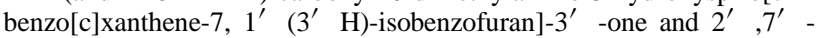
biscarboxyethyl-5(and 6)-carboxyfluorescein", Analytical Biochemistry, Vol. 204, pp. 65-71, 1992.

[9] C. S. Owen, P. Carango, S. Grammer, S. Bobyock, D. B. Leeper, "pHdependent intracellular quenching of the indicator carboxy-SNARF-1", Journal of fluorescence, Vol. 2, pp. 75-80, 1992. 